\title{
Digital Publisher
}

ISSN 2588-0705

\section{Global GAP y su complemento GRASP: Filosofia de Responsabilidad Social Empresarial del Sector Agroalimentario}

Global GAP and its complement GRASP: Philosophy of Corporate Social Responsibility of the Agri-food sector

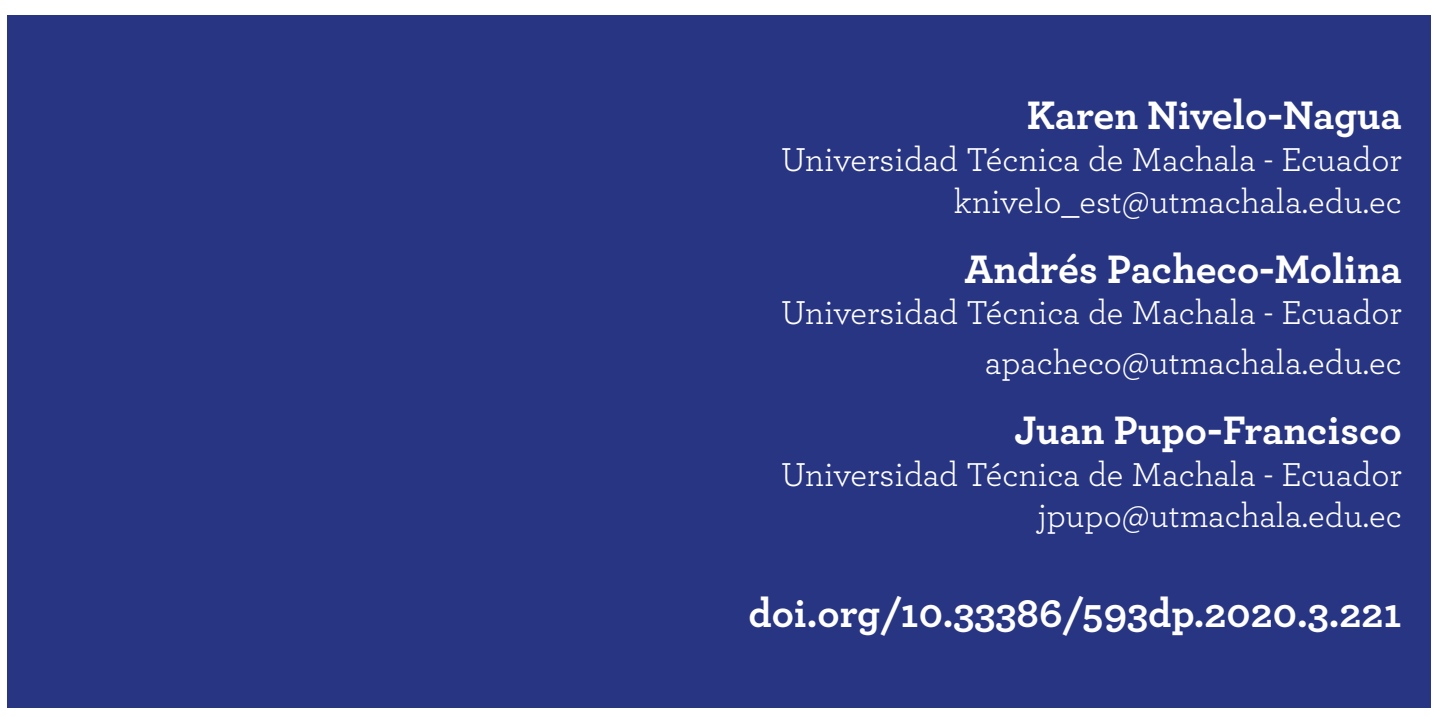

V5-N3 (may-jun) 2020, pp. 93-111 | Recibido: 09 de febrero de 2020 - Aceptado: 27 de febrero de 2020 (2 ronda rev.) 


\section{RESUMEN}

Global GAP, es considerada una norma mundial para las Buenas Prácticas Agrícolas, añadiendo en sus últimos años por las exigencias del mercado, un complemento adicional a su normativa conocido como GRASP (Evaluación de Riesgos para las Prácticas Sociales) que evalúan temas referentes a la salud, seguridad y bienestar de los trabajadores; figurándose el problema de la investigación, en aquellos derechos que hoy en día son vulnerados por organizaciones que no cumplen con las reglamentaciones y leyes tanto nacionales como internacionales a favor de la clase trabajadora. Por tanto, el objetivo principal de este artículo es identificar la incidencia de la aplicación de la normativa Global GAP y su complemento GRASP en el cumplimiento de la filosofía de Responsabilidad Social Empresarial (RSE) para la integración de sostenibilidad del sector agroalimentario. Se aplicó una metodología de carácter descriptiva, con un enfoque cuantitativo basada en 13 indicadores claves que permitieron analizar la percepción de 384 trabajadores con respecto a normativas que conjugan tanto el cumplimiento de la norma como de la RSE a través del software SPSS-23. Los resultados demuestran el compromiso del sector agroalimentario en mejorar las condiciones y calidad de vida de los trabajadores a raíz de su certificación, permitiéndose a ellos mismos crear sostenibilidad y ser parte de un mercado internacional.

Palabras clave: Calidad de vida, Global GAP, GRASP, Responsabilidad Social Empresarial, sector agroalimentario.

Cómo citar este artículo

APA

Nivelo, K., Pacheco, A., \& Pupo, J. (2020). Global GAP y su complemento GRASP: Filosofía de Responsabilidad Social Empresarial del Sector Agroalimentario. 593 Digital Publisher CEIT, 5(3), 93-111. https://doi. org/10.33386/593dp.2020.3.221

Descargar para Mendeley escargar para Mendeley $\mathbf{y}_{1}$ Zotero'

\section{ABSTRACT}

Global GAP, is considered a world standard for Good Agricultural Practices, adding in its last years due to market demands, an additional complement to its regulations known as GRASP (Risk Assessment for Social Practices) that evaluate issues related to health, safety and welfare of workers; figuring out the problem of research, in those rights that today are violated by organizations that do not comply with national and international regulations and laws in favor of the working class. Therefore, the main objective of this article is to identify the incidence of the application of the Global GAP regulations and their GRASP complement in compliance with the Corporate Social Responsibility (CSR) philosophy for the integration of sustainability in the agri-food sector. A descriptive methodology was applied, with a quantitative approach based on 13 key indicators that allowed analyzing the perception of 384 workers with respect to regulations that combine both compliance with the standard and CSR through the SPSS-23 software. The results demonstrate the commitment of the agri-food sector to improve the conditions and quality of life of workers as a result of their certification, allowing themselves to create sustainability and be part of an international market.

Key words: Quality of life, Global GAP, GRASP, Corporate Social Responsibility, agri-food sector. 


\section{Introducción}

La diversidad de los cambios que surgen a diario, en cuanto a la sociedad y a las empresas en general, se torna cada vez más rígida y exigente. Esto, no solo para un nicho específico de mercado o a un segmento en particular, sino para toda organización, independientemente de su clasificación en cuanto a origen, forma de explotación, tamaño, sectores económicos u otra modalidad de categorización al que pertenezcan. De acuerdo a los autores Bohórquez (20 13) y Villacís y Reis (2015), existen varios estudios que revelan y describen a las organizaciones como sistemas no lineales que se encuentran sujetas a los diversos cambios del mercado. Refiriéndose a innovación, patrones del consumidor, políticas medioambientales, empresariales, y una pluralidad de eventos que surgen a partir de la globalización. Sin embargo, el problema de la investigación, aún en la actualidad, radica en la vulnerabilidad de los derechos de los trabajadores, siendo una de las causas principales de los estragos y retrasos con respecto a la evolución de las organizaciones, lo que afecta no solo la parte social sino económica de las mismas.

El sector agroalimentario no es ajeno a las diferentes exigencias del mercado actual en cuanto a calidad y calidez por estar enfocado en diferentes tipos de producción, como insumos agrarios, alimentos para el ganado y su principal enfoque y en la que se centra la presente investigación, la alimentación humana; siendo uno de los sectores más regulados tanto a nivel nacional como internacional por su gran importancia e impacto mundial (Abadía y Melgarejo, 2017). Enfocado propiamente en el caso de Ecuador, país rico en producción agroalimentaria, con diferentes destinos tanto propios como internacionales, la gran parte de su producción es exportada hacia países americanos y europeos, en donde su demanda es relativamente alta, para lo cual se tiene que cumplir con ciertos estándares, normativas y exigencias internacionales a favor de la clase obrera y de la sociedad.
Todos estos cambios han forzado el replanteamiento de nuevas ideologías empresariales. En donde, la base de sus operaciones es el bienestar de todos y cada uno de los involucrados tanto directa e indirectamente a la organización, mismos que pueden verse afectados por las diversas actividades que en ella se ejecuten. Estos son conocidos como stakeholders, elementos valiosos y esenciales a considerar en toda planificación estratégica organizacional (Morán, Rodriguez, Torres, Aguilar, y Villalta, 2016). De acuerdo a Cattaneo y Bocchicchio, (2019) las empresas se enfrentan a nuevos desafíos, no solo en el ámbito tecnológico, sino también organizativo, enmarcados en paradigmas económico-productivos en donde la responsabilidad empresarial es el pilar fundamental para su desarrollo.

Dichas ideologías empresariales, se resumen en tres palabras claves y memorables en el tiempo, como es la Responsabilidad Social Empresarial conocida como RSE, de acuerdo con Jiménez y Pérez, (2016). Muchas de las organizaciones utilizan la RSE como instrumento esencial para mejorar su rentabilidad económica en base a deberes y obligaciones comerciales que trae consigo la aplicación y por ende el compromiso organizacional con esta filosofía. Sin embargo, hasta la actualidad son pocas las empresas, miembros de grupos y organismos, verdaderamente comprometidos y amigables con la sociedad, que cumplen una serie de estándares en beneficio de sus colaboradores, clientes, consumidores, proveedores, e inclusive del medio ambiente y entorno en general (Barros, Retamozo, y González, 2015).

Es allí es donde cabe mencionar la presencia de varios organismos internacionales enfocados propiamente en la Responsabilidad Social Empresarial, como es el caso de la normativa Global GAP (Buenas Prácticas Agrícolas) y su complemento GRASP (Evaluación de Riesgos para las Prácticas Sociales) direccionado a asegurar la inocuidad alimentaria, manejo integrado de plagas, sistema de gestión de calidad, medio ambiente y su biodiversidad y en la que se centra la investigación: la 
protección de los derechos de los trabajadores (GlobalGAP, 2019). Desde esta perspectiva, el objetivo de la presente investigación es identificar la incidencia de la aplicación de la normativa Global GAP con su complemento GRASP en el cumplimiento de la filosofía de Responsabilidad Social Empresarial. Para ello, se propone una metodología de carácter descriptiva, con un enfoque cuantitativo, con la finalidad de determinar la integración de sostenibilidad empresarial y el compromiso de las organizaciones en el mejoramiento de la calidad de vida de los trabajadores y de la sociedad en general.

\section{Desarrollo}

En la mayoría de las naciones, la evolución del individuo y de sus estilos de vida ha dado pasos agigantados en los cambios de comportamientos alimenticios de cada uno de ellos. En donde, la exigencia de la calidad es el factor base para los nuevos requerimientos que enfrentan las organizaciones en cuanto a salud, nutrición, inocuidad alimentaria y seguridad laboral (Ruíz, 2016). El inicio de una nueva era comienza con el surgimiento de los Objetivos de Desarrollo Sostenible, impulsados por la ONU en el año 2015. Tras varias décadas de lucha contra la inseguridad alimentaria en los cuales, países miembros de todo el mundo, tanto gobiernos y organizaciones como ciudadanía en general, se unen a la causa mediante el cumplimiento de nuevas leyes, políticas y normativas impuestas por organismos internacionales para un beneficio global y conjunto (FAO, FIDA, UNICEF, PMA y OMS, 2018).

El sector agroalimentario es el principal motor de desarrollo y crecimiento económico y social de las regiones latinoamericanas. Se presentan rigurosos procesos de cambios a escala nacional e internacional, con un esfuerzo direccionado a la implementación de nuevas medidas sociales y económicas, que influyen en los grupos de interés de cada región y mercado en particular (Calderón y Kolbe, 2016). Según García, Caraus, Iglesias, y Maldonado, (2018) No es ajeno el alto grado de impacto que prevalece sobre el sector agroalimentario y su entorno, en cuanto a medidas sobre el manejo de tierra, efectos sobre la fertilidad del suelo, la salinidad y la acidez, deterioros en la materia orgánica y biodiversidad e incluso en la gestión de residuos que todo este sector tendrá que asumir como resultado de su productividad.

Según, Zivko, Bogetic, y Dordevic, (2015) las compañias agroalimentarias se encuentran a un gran desafío por sobrevivir o simplemente quedarse estancadas en el pasado debido a los diversos problemas de calidad, seguridad alimentaria, seguridad laboral y estándares que tienen que cumplir hoy en día para estar a la par de los nuevos mecanismos impuestos por los organismos procuradores de dichas ideologías. Una de las iniciativas mundiales que dan paso a la solución de dichos problemas es la aplicación de la normativa Global GAP, misma que avala y certifica a los diversos consumidores de todo el mundo la calidad del producto que éste está comprando y por ende consumiendo, así como sus diversos procesos laborales (Rincon, Figueredo, y Salazar, 2015).

Global GAP tuvo sus inicios por un sector minorista británico, quienes empezaron a enfatizar su preocupación por la inocuidad de los alimentos que consumían sus individuos, por la salud y bienestar de los diferentes trabajadores, por los métodos de producción, así como del impacto ambiental que dichas organizaciones producían con el tiempo (Zivko, Bogetic, y Dordevic, 2015). El desarrollo de un sistema de certificación que englobe las Buenas Prácticas Agrícolas, fue lo que dio lugar a la creación de EUREPGAP en el año de 1997, el cual se centró en permitir la armonización de las normas y procedimientos organizacionales, cobrando importancia a escala mundial a raíz de la globalización (Rincon, Figueredo, y Salazar, 2015).

Dicha normativa se generó, además, por la necesidad de crear protocolos y reglas comunes de certificación, en cuanto a la utilización de productos para las cosechas, el manejo de plagas, malezas, pesticidas, fertilizantes, fungicidas entre otros productos 
claves para el manejo agrícola que no afecten la seguridad alimentaria de los individuos de cada región (Rincon, Figueredo, y Salazar, 2015); Con ello se pudo reflejar el aseguramiento de los requerimientos de todos y cada uno de los consumidores en la producción de los diferentes países interesados en mejorar sus procesos sociales, económicos y ambientales, dando paso en el 2007 a cambiar su nombre actual por Global GAP (GlobalGAP, 2019 ).

Las actuales exigencias del mundo globalizado han dado lugar al deslumbre de un complemento adicional a la normativa Global GAP, que es el GRASP. Este abarca temáticas de suma relevancia integral como lo es la salud, seguridad y bienestar de todos y cada uno de los trabajadores que intervienen en los diferentes procesos productivos de las áreas agrícolas certificadas, demostrando así su compromiso con la Responsabilidad Social Empresarial (GlobalGAP, 2019).

Según Wulf(2018) se definea la Responsabilidad Social Empresarial como la integración de elementos tanto sociales como ambientales en relación a las diversas actividades y operaciones del giro de un negocio u organización con las partes relacionadas de la misma. Se entiende que, con el pasar del tiempo, la globalización no solo ha permitido la creciente comunicación entre los distintos países del mundo entero, sino que también ha permitido que empresas de todo el continente se enfoquen en una mayor contribución y mejoramiento de la parte social, económica y ambiental de sus regiones. Más allá del cumplimiento de las diferentes normas y leyes impuestas por los grandes organismos internacionales, las empresas han creado conciencia del impacto de sus operaciones sobre la sociedad en general. (Marquina y Reficco, 2015).

El surgimiento de la Responsabilidad Social Empresarial, considerada como una contribución de las diferentes empresas del medio al desarrollo humano sostenible, genera un impacto positivo con cada una de sus actividades a través del compromiso y confianza de las organizaciones hacia sus empleados y, por ende, hacia la sociedad o partes interesadas de la misma a las que se conoce como stakeholders (López, Perusquía, Valladares, Villalón, y Ramírez, 2015).

Los stakeholders hacen referencia propiamente a los individuos, no solamente internos de la organización como lo son los trabajadores, sino también al entorno el cual les rodea, como es el caso de los clientes, proveedores, organismos sociales, y todo ente que se vea afectado por las diferentes decisiones organizacionales (Uribe, Orjuela, y Moreno, 2016).

El enfoque de los stakeholders facilita a las organizacionesirmásallá detodolomencionado anteriormente, pues permite personificar, clasificar, y prevalecer los mercados o públicos. Por ende, estos han de asumir compromisos sociales y medioambientales para luego poder modular acciones para el cumplimiento de las diversas necesidades de cada grupo en cuestión (Almeida y Arrechavaleta, 2018). Dentro del enfoque de la responsabilidad social relacionada intrínsecamente con los stakeholders se abarca dos dimensiones, una interna y otra externa, mismas que se relacionan directa $e$ indirectamente para contribuir significativamente a los objetivos organizacionales de una empresa o institución.

Dentro de la dimensión interna y en la que se centra la investigación, cabe destacar las prácticas responsables que afectan a los trabajadores de las organizaciones en cuanto a situaciones como la inversión en salud y seguridad ocupacional, recursos humanos, impacto ambiental, gestión de los recursos naturales entre más variables afines al caso (García, Guzmán, y Mendoza, 2017). En cambio, el enfoque de la dimensión externa, se enfatiza en la contribución al desarrollo de las comunidades aledañas a las organizaciones, pues al hacer referencia al término de sostenibilidad se busca que las empresas sean perdurables en el tiempo, concepto que impide que las organizaciones con una Responsabilidad Social Empresarial muy arraigada perjudiquen a las zonas o regiones en donde su empresa 
funciona (Tapia, Gavilánez, Jácome, y Balseca, 2018).

Se debe tener en consideración que un sector, en este caso el agroalimentario, es verdaderamente responsable cuando actúa bajo los términos del desarrollo sostenible y de la perdurabilidad en el tiempo. Lo cual viene arraigado con el compromiso con la sociedad y la preservación medioambiental (Antelo y Robaina, 2014). Por dicha razón, organismos internacionales como la FAO (Food and Agriculture Organization) o la FDA (Food and Drug Administration) han tomado cartas en el asunto y han propiciado medidas de mejoramiento y protección de los alimentos que precautelen, en primer lugar, la seguridad alimentaria $y$, por ende, la sostenibilidad social y ambiental en gran parte del mundo, llegando a países y naciones desarrolladas y subdesarrolladas, con producción rica en alimentos, como es el caso de Ecuador (García y Wahren, 2016).

Hay que señalar que uno de los esquemas de sostenibilidad social y ambiental más predominante utilizado en el sector agroalimentario ecuatoriano es la certificación Global GAP (Olmos, 20 17). Es relevante destacar a dicho sector, como la base fundamental de su economía nacional en cuanto a ingresos monetarios y generación de empleo tanto directo e indirecto a un sin número de familias que basan su sustento diario en esta actividad y las que vienen consigo (Burbano y Fernández , 2018).

El Banco Central del Ecuador (BCE) en su estudio y análisis estadístico del 2019 presenta las cifras del crecimiento de la economía ecuatoriana, en donde el sector agrícola y agroalimentario tiene un rol destacable en dicho desarrollo. En Io concerniente a la evolución interanual del VAB sectorial correspondiente a una comparación entre el segundo trimestre del 2019 vs el segundo trimestre del 2018, determina que el sector en mención, presenta una variación del 1,8\%, destacando principalmente a las exportaciones de banano ecuatoriano en el mundo (Banco Central del Ecuador, 2019).
Además, cabe mencionar que el sector agrícola y la industria transformadora general alrededor de 2,5 millones de puestos de trabajos en el Ecuador, cifra bastante alta en los últimos tiempos. (El Comercio, 2019)

El Ministerio de Producción, Comercio Exterior, Inversiones y Pesca presenta en el periodo de septiembre 2019 datos con los que contrasta la participación de exportaciones no petroleras, como el banano, en términos de volumen en un 63\% de las exportaciones ecuatorianas. Se produce un crecimiento del 2\%, valor relevante para la economía ecuatoriana, pues, a medida que este rubro aumenta, la situación tanto social y empresarial también lo hace, precautelando de todas las maneras posibles, la soberanía alimentaria (Ministerio de Producción, Comercio Exterior, Inversiones y Pesca, 2019).

Según Ruíz (2016) el desarrollo económico de las naciones tiene su base principal en el ejercimiento de la soberanía alimentaria de sus diferentes regiones y sectores. Sin embargo, debido a las exigencias del mercado las mismas deben de apegarse a normativas tanto nacionales como internacionales que darán un plus adicional a su producción local (Martínez y Rosset, 2015).

EnEcuador, se trata en su mayoría de precautelar la soberanía alimentaria, pero, más allá de ello, se da trata de dar realce al cumplimiento de las normas internacionales y, por consiguiente, a la exportación de los frutos, dejando de ser normas opcionales para convertirse en obligatorias para todo exportador. Así, se cambian modelos de producción tradicionales por modelos innovadores enfocados en la RSE, en donde no solo se vea reflejada su producción si no también la de su gente. La relación existente entre la normativa Global GAP y su complemento GRASP, permite a los productores, establecer y determinar un sistema de gestión social en cada una de sus actividades y operaciones diarias, además de ofrecerles a los compradores un plus y garantía adicional en su fruta certificada por los organismos internacionales vigentes (GlobalGAP, 2019). 
Dentro de la dimensión interna de los stakeholders, mencionados anteriormente, se presenta en primer plano a los trabajadores. Al contar con esta normativa se obliga y, a la vez, se motiva a los empresarios a afiliar a todos y cada uno de sus colaboradores; a ofrecerles un salario justo y equitativo, dependiendo de sus funciones y actividades diarias; a la elección de un representante de trabajadores que tenga voz y voto en cuanto al bienestar de los mismos; al mejoramiento de la salud y seguridad en el lugar de trabajo, que incluye la entrega de equipos de protección personal, botiquín y entrega de equipos ergonómicos. También deben efectuarse reuniones con los trabajadores con la finalidad de conocer tanto fortalezas como debilidades del puesto de labores, entre una pluralidad más de beneficios que esta normativa trae consigo (GlobalGAP, 20191

En cuanto a demás partes relacionadas, se tiene a los compradores, quienes poseen una garantía adicional por la compra de sus productos. Estos están relacionados con la sociedad en general, no solo del país en cuestión sino de todos aquellos países compradores y consumidores de la fruta ecuatoriana, ya que al aplicar la norma Global GAP y su complemento GRASP se da clara prioridad a la salud, seguridad y bienestar de los trabajadores, Io cual contribuye al mejoramiento de su calidad de vida y por ende al mejoramiento de la sociedad, principales consumidores de los alimentos ofertantes por los pequeños, medianos y grandes productores de cada región en particular (GlobalGAP, 20191

\section{Metodología}

La presente investigación se apoyó en una metodología de carácter descriptiva, con un enfoque cuantitativo, en el que se determina la incidencia de la aplicación de la normativa Global GAP y su complemento GRASP en el cumplimiento de la filosofía de RSE para la integración y sostenibilidad del sector agroalimentario. Se identifican 13 indicadores principales, tanto de la normativa como de la RSE, a través de datos obtenidos mediante la aplicación de instrumentos de investigación, detallados más adelante, para luego ser debidamente procesados mediante el respectivo análisis estadístico inferencial.

Partiendo, en primera instancia, con un muestreo aleatorio estratificado de la parte obrera del sector agroalimentario ecuatoriano, con un tamaño de la muestra calculado en base a un nivel de confianza del noventa y cinco por ciento (95\%) y un margen de error del cinco por ciento (5\%). El levantamiento de la información fue realizado a través de la herramienta digital de Google Forms para luego ser exportado al software estadísticoinformático SPSS-23. Se inició asignando valores a cada una de las variables del instrumento, tomando en consideración como primera fase las preguntas estructuradas con reactivos dicotómicos en el que "si" equivale a 1 y "no" a 2, para luego proceder con la representación gráfica de Ggraph (Anderson, Sweeney y Williams, 2008).

Los reactivos politómicos, son representados mediante la utilización de escalas de Likert, donde 1 corresponde a "insatisfecho", 2 a "algo insatisfecho", 3 a "neutral", 4 a "algo satisfecho" y 5 a "muy satisfecho"; con los reactivos de frecuencia, en donde 1 corresponde a "nunca", 2 a "raras veces", 3 a "a veces", 4 a "a menudo" y 5 a "frecuentemente". Otros reactivos se cuantifican con valores donde, 1 corresponde a "Totalmente en desacuerdo", 2 a "En desacuerdo", 3 a "Parcialmente", 4 a "De acuerdo" y 5 a "Totalmente de acuerdo" (Anderson, Sweeney y Williams, 2008).

La segunda fase corresponde al análisis descriptivo de la información obtenida y valorizada, englobando el cálculo de la media, mediana, moda, desviación estándar, varianza, asimetría, curtosis, y percentiles. Estos cálculos estadísticos relevantes servirán como preámbulo de la tercera fase, en la que dichos datos se verán reflejados en un diagrama de cajas, demostrando su concentración (Lind, Marchal y Wathen, 20121. 
La cuarta fase hace referencia al análisis inferencial de los datos obtenidos a través del coeficiente de Pearson. Esto fue aplicado con el objetivo de determinar cuánto incide una variable sobre la otra, demostrándose, en la quinta fase, los elementos que contengan una mayor concentración mediante la elaboración de tablas cruzadas para finalizar con la investigación (Lind, Marchal y Wathen, 2012).

\section{Resultados}

Cabe aclarar que el resultado del cálculo de la muestra antes descrita en la metodología, a través de la fórmula (1), en donde $\mathrm{N}$ indica el tamaño de la población, que actualmente es desconocida; z es la puntuación estándar relativa al nivel de confianza del 95\%, que toma el valor 1.96; p es la probabilidad favorable, que se toma como desconocida y tomaría el valor 0.50; q es la probabilidad en contra, complemento de la anterior, siendo equivalente a 0.50 y d corresponde al margen de error del 5\%, dando como resultado un total de 384 individuos por encuestar.

$$
n=\frac{z^{2} \times p \times q}{d^{2}}
$$

La tabulación de los datos obtenidos permitió identificar la incidencia de la normativa Global GAP y su complemento GRASP en el cumplimiento de la RSE a través de una serie de análisis, tanto descriptivos como inferenciales. Comenzando en primer plano con indicadores representados gráficamente mediante Ggraph, donde se demuestra cómo esta normativa ha influenciado en algunos aspectos organizacionales a favor, como es el caso de la existencia de un representante de los empleados para reclamaciones. El 39.84\% demuestra una respuesta negativa frente al mayor porcentaje que muestra una respuesta positiva equivalente al 60.16\%, lo que indica el cumplimiento del Título V del Código de trabajo Ecuatoriano con respecto al derecho de las asociaciones de trabajadores y de los conflictos colectivos (Ministerio de Trabajo, 2020). Véase Gráfico 1.
Así mismo, con el indicador de la estabilidad laboral, en el que un 26.11\% de los trabajadores encuestados manifestó su inestabilidad, frente a un $73.89 \%$ que manifestó su conformidad, indicando el cumplimiento de uno de los factores más apremiantes de la calidad de vida laboral (Patlán, 2016). Véase Gráfico 2.

La misma situación se presenta con el indicador de Afiliación en el IESS (Instituto Ecuatoriano de Seguridad Sociall) en el que un 25\% de los trabajadores aún no es afiliado, frente a un 75\% que si lo es, lo que representa cómo a raíz de la aplicación de la normativa Global GAP y su complemento GRASP, las empresas se han preocupado por brindar a sus obreros mejores condiciones de vida y derechos fundamentales para su salud y seguridad ocupacional tal como lo indican las listas de verificación del centro de documentación de Global Gap (GlobalGAP, 20191. Véase Gráfico 3.

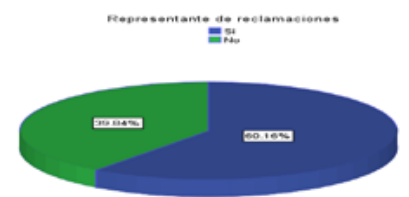

Gráfico 1 Representante de reclamaciones.

Fuente: Elaboración propia.

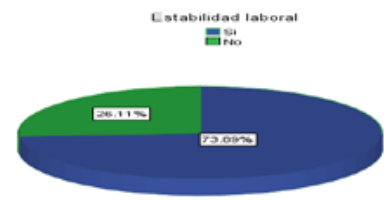

Gráfico 2 Estabilidad laboral

Fuente: Elaboración propia. 


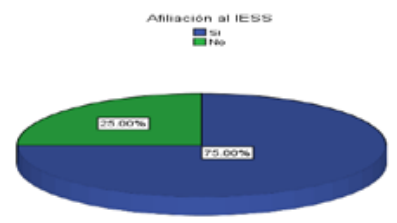

Gráfico 3 Afiliación al IESS

Fuente: Elaboración propia.

Las principales medidas de dispersión dentro del análisis descriptivo permiten determinar la concentración de los datos obtenidos según los diversos criterios o indicadores estudiados Instalaciones de trabajo adecuadas, acceso a sanitarios, acceso a áreas limpias de consumo de alimentos, acceso a áreas de descanso, remuneración justa según las funciones, participación en capacitaciones, disponibilidad de materiales y herramientas, percepción de la seguridad y salud ocupacional, desarrollo y participación de los trabajadores y la vinculación y compromiso con la comunidad). En la Tabla 1 se muestran estadísticas en los que es importante destacar el indicador de "instalaciones de trabajo adecuadas" por su mayor concentración de datos, con una media de 4.68 y con una desviación estándar y varianza mínima de 0.501 y 0.251 respectivamente, a diferencia del indicador de "participación en capacitaciones" con la media más baja de 4.00, y con una desviación estándar y varianza muy alta de 1.123 y 1.261 respectivamente, denotándose una mayor variabilidad en cuanto a las 384 respuestas del instrumento por parte de los obreros del sector agroalimentario y, por ende, un indicador clave en el que las organizaciones deben de poner mayor énfasis. La distribución de los datos antes mencionados se puede visualizar a través de la representación gráfica, mediante un diagrama de cajas que se muestra en el Gráfico 4. 


\begin{tabular}{|c|c|c|c|c|c|c|c|c|c|c|c|c|c|c|}
\hline 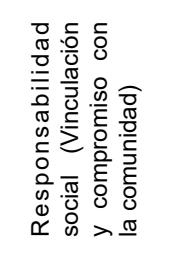 & $\underset{\infty}{\infty}$ & - & $\stackrel{\infty}{\stackrel{+}{+}}$ & $\underset{+}{\stackrel{+}{*}}$ & n & $\stackrel{\mathscr{N}}{\stackrel{\leftrightarrow}{0}}$ & $\underset{\infty}{\stackrel{N}{\infty}}$ & 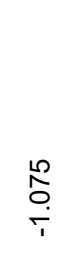 & $\stackrel{\mathscr{N}}{\stackrel{\sim}{\longrightarrow}}$ & 京 & 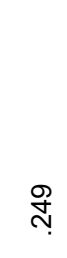 & $\begin{array}{l}\underset{+}{\circ} \\
\end{array}$ & $\underset{+}{\stackrel{8}{+}}$ & $\begin{array}{l}8 \\
\text { in }\end{array}$ \\
\hline 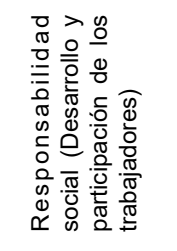 & 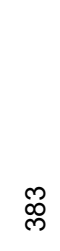 & - & 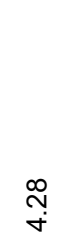 & $\begin{array}{l}8 \\
\text { in }\end{array}$ & م & $\bar{\sigma}$ & $\underset{\infty}{\infty}$ & $\stackrel{\substack{\mathrm{D} \\
\hdashline}}{\leftarrow}$ & $\stackrel{\sim}{\stackrel{N}{c}}$ & $\begin{array}{l}\stackrel{\circ}{\infty} \\
\stackrel{\leftrightarrow}{\leftarrow}\end{array}$ & 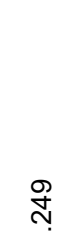 & $\begin{array}{l}\stackrel{8}{\circ} \\
+\end{array}$ & \&: & $\underset{i}{\stackrel{8}{0}}$ \\
\hline 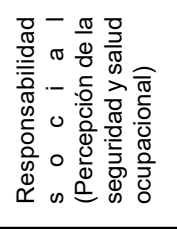 & 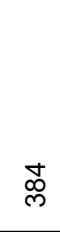 & 0 & 号 & $\underset{i}{8}$ & in & 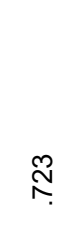 & ִָ & $\begin{array}{l}\bar{\varnothing} \\
\stackrel{\leftrightarrow}{\prime}\end{array}$ & $\stackrel{\stackrel{\sim}{ }}{\leftarrow}$ & 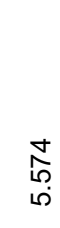 & $\stackrel{\infty}{\stackrel{+}{*}}$ & $\underset{+}{\stackrel{+}{\circ}}$ & $\underset{i}{8}$ & $\underset{i}{\stackrel{8}{0}}$ \\
\hline 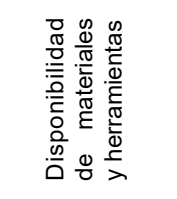 & $\underset{\infty}{\infty}$ & - & 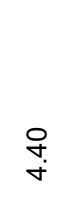 & $\underset{\text { if }}{8}$ & م & $\stackrel{\mathbb{N}}{\mathrm{N}}$ & 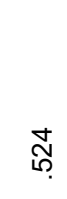 & & $\stackrel{\mathscr{N}}{\stackrel{\sim}{\longrightarrow}}$ & $\stackrel{\frac{9}{6}}{6}$ & 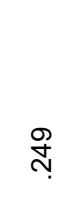 & $\underset{+}{\stackrel{\circ}{*}}$ & $\underset{i}{\stackrel{8}{0}}$ & $\underset{i}{8}$ \\
\hline 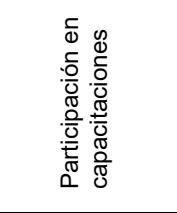 & 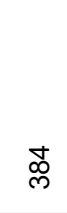 & 0 & $\underset{+}{\stackrel{8}{+}}$ & $\underset{+}{\stackrel{8}{+}}$ & ம & 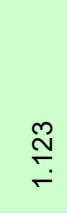 & 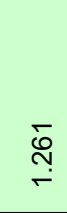 & $\frac{\hat{0}}{\dot{\varphi}}$ & $\stackrel{\mathscr{N}}{\mathrm{N}}$ & 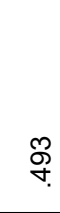 & $\stackrel{\infty}{\stackrel{\infty}{N}}$ & 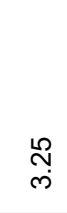 & $\underset{+}{\stackrel{8}{+}}$ & 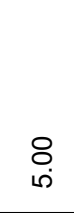 \\
\hline 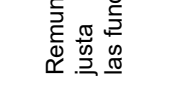 & 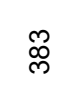 & - & $\underset{\forall}{\check{F}}$ & $\begin{array}{l}\stackrel{8}{+} \\
\dot{+}\end{array}$ & $\nabla$ & शे & ஜ్రి & $\begin{array}{c}\text { o } \\
\vdots \\
i \\
i\end{array}$ & $\stackrel{\mathscr{N}}{\stackrel{\sim}{\sim}}$ & 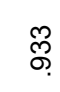 & $\stackrel{\text { g }}{\underset{\text { T}}{ }}$ & $\underset{+}{\stackrel{8}{ }}$ & $\underset{+}{\stackrel{8}{+}}$ & $\begin{array}{l}8 \\
i\end{array}$ \\
\hline 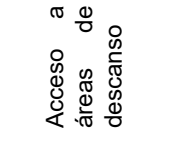 & 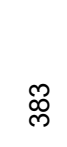 & - & $\underset{\sim}{\stackrel{\sim}{+}}$ & $\underset{+}{\stackrel{\leftrightarrow}{+}}$ & ம & 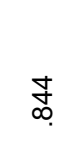 & $\stackrel{N}{T}$ & 趈 & $\stackrel{\stackrel{N}{ }}{\sim}$ & $\begin{array}{l}\text { న్రి } \\
\text { N }\end{array}$ & $\stackrel{g}{\stackrel{9}{N}}$ & $\begin{array}{l}\stackrel{8}{\circ} \\
+\end{array}$ & $\underset{+}{\stackrel{8}{+}}$ & $\underset{\text { in }}{8}$ \\
\hline 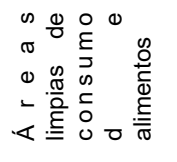 & 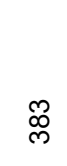 & - & 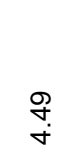 & $\underset{\text { Oे }}{8}$ & م & $\stackrel{0}{\stackrel{0}{r}}$ & $\stackrel{N}{5}$ & 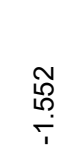 & $\stackrel{\mathscr{N}}{\sim}$ & $\begin{array}{l}\widetilde{O} \\
\text { లె } \\
\text {. }\end{array}$ & $\stackrel{g}{\stackrel{9}{N}}$ & $\underset{+}{\stackrel{+}{0}}$ & $\underset{i}{8}$ & $\underset{i}{8}$ \\
\hline 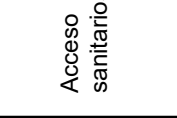 & 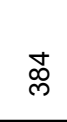 & 0 & $\begin{array}{l}\stackrel{L}{\circ} \\
\stackrel{\sim}{*}\end{array}$ & $\underset{\text { i }}{8}$ & ம & $\overline{8}$ & $\stackrel{\infty}{\stackrel{\infty}{f} .}$ & 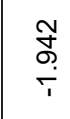 & $\stackrel{\mathscr{N}}{\stackrel{ }{\sim}}$ & $\begin{array}{l}0 \\
0 \\
0 \\
i\end{array}$ & $\stackrel{\infty}{\stackrel{\infty}{N}}$ & $\begin{array}{l}\stackrel{8}{\circ} \\
\leftarrow\end{array}$ & $\underset{\text { i }}{8}$ & $\underset{i}{8}$ \\
\hline 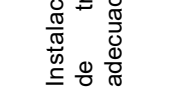 & 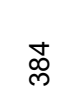 & o & $\begin{array}{l}\infty \\
\stackrel{0}{+} \\
\dot{+}\end{array}$ & 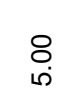 & ما & దَ & $\stackrel{\Gamma}{\stackrel{\Gamma}{n}}$ & $\stackrel{\stackrel{m}{c}}{\leftarrow}$ & $\stackrel{\mathscr{N}}{\stackrel{\sim}{\sim}}$ & : & $\stackrel{\infty}{\stackrel{0}{̣}}$ & 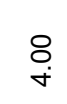 & $\underset{i \infty}{\stackrel{8}{0}}$ & $\underset{i}{\stackrel{8}{0}}$ \\
\hline & $\frac{\frac{0}{0}}{i \frac{10}{3}}$ & $\begin{array}{l}\frac{0}{0} \\
\frac{0}{\overline{0}} \\
\overline{0} \\
0\end{array}$ & & & & $\begin{array}{l}\text { 离 } \\
\text { c. }\end{array}$ & & & 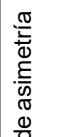 & & $\begin{array}{l}\frac{\omega}{0} \\
\frac{0}{5} \\
\frac{5}{0} \\
\frac{0}{0}\end{array}$ & $\stackrel{\llcorner}{\sim}$ & in & $\stackrel{R}{\wedge}$ \\
\hline & $z$ & & $\frac{\frac{\pi}{0}}{\frac{0}{0}}$ & 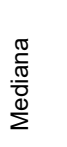 & $\begin{array}{l}\text { 类 } \\
\text { 20 }\end{array}$ & 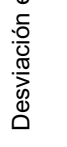 & 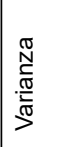 & 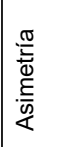 & 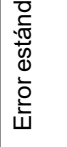 & $\begin{array}{l}\frac{.0}{0} \\
\frac{0}{5} \\
0 \\
0\end{array}$ & 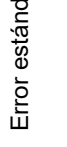 & 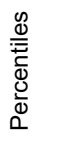 & & \\
\hline
\end{tabular}




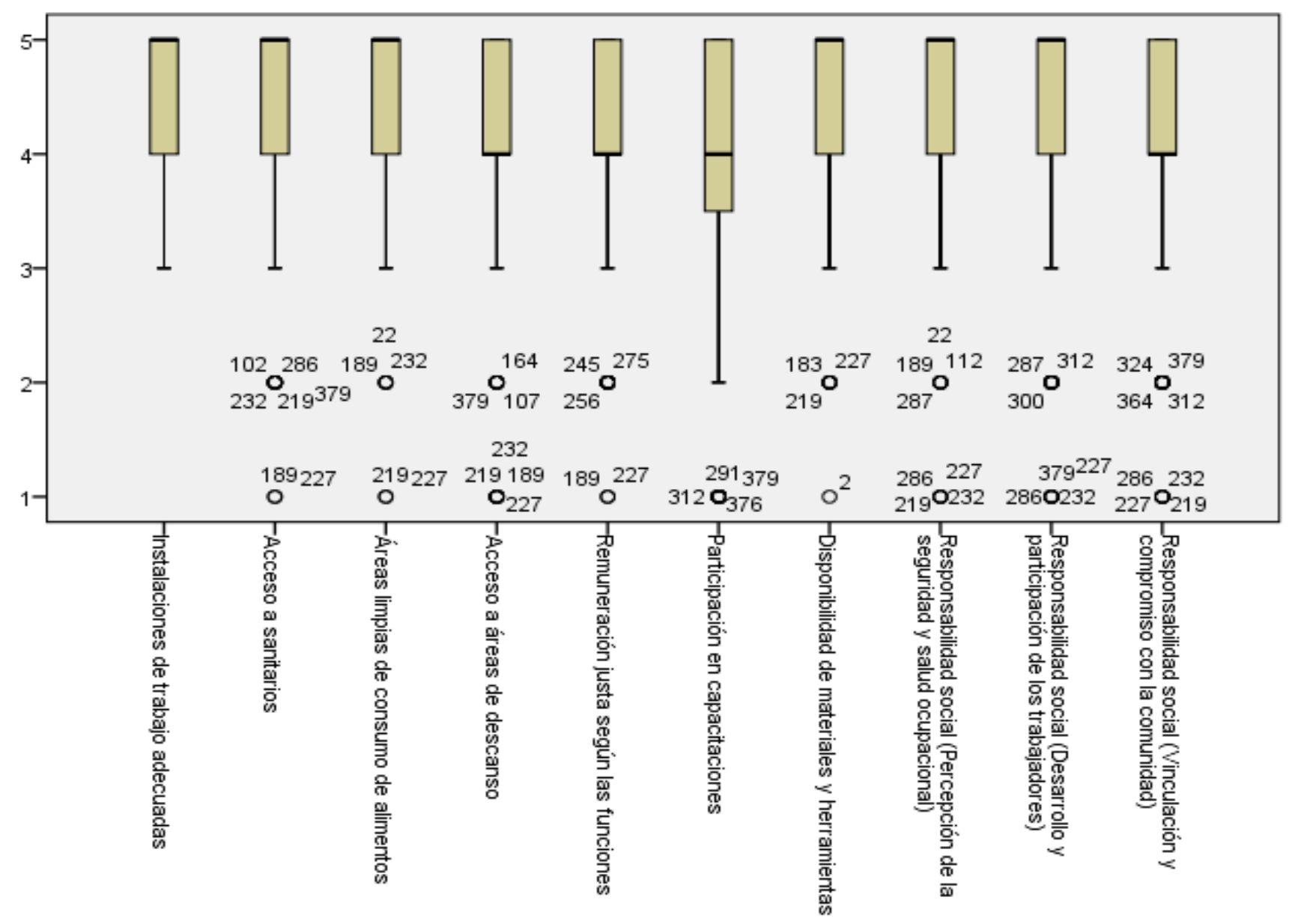

Gráfico 4. Diagrama de cajas

Fuente: Elaboración propia.

En el análisis inferencial, tal como se muestra en la Tabla 2 de correlaciones, se permitió evaluar en qué medida se puede predecir los valores de una variable sobre otra, como es el caso de las variables de "acceso a áreas de descanso" y "áreas limpias de consumo de alimentos". Se denota un coeficiente de correlación de Pearson con un valor de .853, considerado dentro del calificativo de correlación positiva fuerte (Lind, Marchal y Wathen, 2012). Así mismo, sucede con las variables de "Percepción de la seguridad y salud ocupacional" y "Desarrollo y participación de los trabajadores", en el que se demuestra un correlación de .836; En las variables de "Vinculación y compromiso con la comunidad" y "Percepción de la seguridad y salud ocupacional" con una correlación de 805 y en las variables de "Vinculación y compromiso con la comunidad" y "Desarrollo y participación de los trabajadores" con una correlación de .913, denotándose claramente cómo incide una variable sobre la otra; incidencia que puede ser apreciada con mayor detalle en las tablas cruzadas, 3, 4, 5 y 6. 


\begin{tabular}{|c|c|c|c|c|c|c|c|c|c|c|c|}
\hline & & $\begin{array}{l}\text { Instala } \\
\text { ciones } \\
\text { de } \\
\text { trabaj } \\
0 \\
\text { adecu } \\
\text { adas }\end{array}$ & $\begin{array}{l}\text { Acce } \\
\text { so a } \\
\text { sanit } \\
\text { arios }\end{array}$ & $\begin{array}{l}\text { Areas } \\
\text { limpias } \\
\text { de } \\
\text { consum } \\
0 \quad \text { de } \\
\text { aliment } \\
\text { os }\end{array}$ & $\begin{array}{l}\text { Acceso } \\
\text { a áreas } \\
\text { de } \\
\text { descan } \\
\text { so }\end{array}$ & $\begin{array}{l}\text { Remun } \\
\text { eración } \\
\text { justa } \\
\text { según } \\
\text { las } \\
\text { funcion } \\
\text { es }\end{array}$ & $\begin{array}{l}\text { Partici } \\
\text { pació } \\
\mathrm{n} \text { en } \\
\text { capaci } \\
\text { tacion } \\
\text { es }\end{array}$ & $\begin{array}{l}\text { Disponi } \\
\text { bilidad } \\
\text { de } \\
\text { material } \\
\text { es y } \\
\text { herrami } \\
\text { entas }\end{array}$ & $\begin{array}{l}\text { Respons } \\
\text { abilidad } \\
\text { social } \\
\text { (Percepci } \\
\text { ón de la } \\
\text { segurida } \\
\text { d y salud } \\
\text { ocupacio } \\
\text { nal) }\end{array}$ & $\begin{array}{l}\text { Respon } \\
\text { sabilida } \\
\text { d social } \\
\text { (Desarr } \\
\text { ollo y } \\
\text { particip } \\
\text { ación } \\
\text { de los } \\
\text { trabajad } \\
\text { ores) }\end{array}$ & $\begin{array}{l}\text { Respon } \\
\text { sabilida } \\
\text { d social } \\
\text { (Vincul } \\
\text { ación y } \\
\text { compro } \\
\text { miso } \\
\text { con la } \\
\text { comuni } \\
\text { dad) }\end{array}$ \\
\hline \multirow{3}{*}{$\begin{array}{l}\text { Instalaci } \\
\text { ones de } \\
\text { trabajo } \\
\text { adecua } \\
\text { das }\end{array}$} & $\begin{array}{l}\text { Correla } \\
\text { ción de } \\
\text { Pearso } \\
n\end{array}$ & 1 &.$^{793^{\circ}}$ & $.756^{\circ}$ & $.691^{*}$ & $.527^{\circ}$ & $.444^{*}$ & $.533^{*}$ & $.650^{\circ}$ & $.634^{*}$ & $.570^{\circ}$ \\
\hline & $\begin{array}{l}\text { Sig. } \\
\text { (bilater } \\
\text { al) }\end{array}$ & & .000 & .000 & .000 & .000 & .000 & .000 & .000 & .000 & .000 \\
\hline & $\overline{\mathrm{N}}$ & 384 & 384 & 383 & 383 & 383 & 384 & 383 & 384 & 383 & 383 \\
\hline \multirow[t]{3}{*}{$\begin{array}{l}\text { Acceso } \\
\text { a } \\
\text { sanitari } \\
\text { os }\end{array}$} & $\begin{array}{l}\text { Correla } \\
\text { ción de } \\
\text { Pearso } \\
n\end{array}$ & $.793^{*}$ & 1 & $.758^{*}$ & $.730^{*}$ & $.586^{*}$ & $.459^{*}$ & $.552^{*}$ & $.750^{*}$ & $677^{\circ}$ & $609^{-}$ \\
\hline & $\begin{array}{l}\text { Sig. } \\
\text { (bilater } \\
\text { al) }\end{array}$ & .000 & & .000 & .000 & .000 & .000 & .000 & .000 & .000 & .000 \\
\hline & $\bar{N}$ & 384 & 384 & 383 & 383 & 383 & 384 & 383 & 384 & 383 & 383 \\
\hline \multirow{3}{*}{$\begin{array}{l}\text { Areas } \\
\text { limpias } \\
\text { de } \\
\text { consum } \\
0 \quad \text { de } \\
\text { aliment } \\
\text { os }\end{array}$} & $\begin{array}{l}\text { Correla } \\
\text { ción de } \\
\text { Pearso } \\
n\end{array}$ & $.756^{*}$ & $.758^{\circ}$ & 1 & $.853^{*}$ & $.664^{*}$ & $.566^{\circ}$ & $.595^{\circ}$ & $.732^{*}$ & $.723^{*}$ & $.689^{\circ}$ \\
\hline & $\begin{array}{l}\text { Sig. } \\
\text { (bilater } \\
\text { al) }\end{array}$ & .000 & .000 & & .000 & .000 & .000 & .000 & .000 & .000 & .000 \\
\hline & $\bar{N}$ & 383 & 383 & 383 & 383 & 382 & 383 & 382 & 383 & 382 & 382 \\
\hline \multirow[t]{3}{*}{$\begin{array}{l}\text { Acceso } \\
\text { a áreas } \\
\text { de } \\
\text { descan } \\
\text { so }\end{array}$} & $\begin{array}{l}\text { Correla } \\
\text { ción de } \\
\text { Pearso } \\
n\end{array}$ & $.691^{*}$ & $.730^{\circ}$ & $.853^{*}$ & 1 & $.669^{\circ}$ & $.604^{*-}$ & $.609^{*}$ & $.724^{*-}$ & $.737^{\circ}$ & $.723^{*}$ \\
\hline & $\begin{array}{l}\text { Sig. } \\
\text { (bilater } \\
\text { al) }\end{array}$ & .000 & .000 & .000 & & .000 & .000 & .000 & .000 & .000 & .000 \\
\hline & $\bar{N}$ & 383 & 383 & 383 & 383 & 382 & 383 & 382 & 383 & 382 & 382 \\
\hline \multirow{2}{*}{$\begin{array}{l}\text { Remun } \\
\text { eración } \\
\text { justa } \\
\text { según } \\
\text { las } \\
\text { funcion } \\
\text { es }\end{array}$} & $\begin{array}{l}\text { Correla } \\
\text { ción de } \\
\text { Pearso } \\
n\end{array}$ & $.527^{\circ}$ & $.586^{\circ}$ & $.664^{*}$ & $.669^{*}$ & 1 & $.629^{*}$ & $.614^{*}$ & $.652^{*}$ & $.656^{\circ}$ & $.653^{*}$ \\
\hline & $\begin{array}{l}\text { Sig. } \\
\text { (bilater } \\
\text { al) }\end{array}$ & .000 & .000 & .000 & .000 & & .000 & .000 & .000 & .000 & .000 \\
\hline
\end{tabular}




\begin{tabular}{llllllllllll}
\hline & $\mathrm{N}$ & 383 & 383 & 382 & 382 & 383 & 383 & 382 & 383 & 382 & 382 \\
\hline $\begin{array}{l}\text { Particip } \\
\text { ación } \\
\text { en } \begin{array}{l}\text { Correla } \\
\text { capacit }\end{array}\end{array}$ & $\begin{array}{l}\text { Pearso } \\
\text { aciones }\end{array}$ & $.444^{*}$ & $.459^{*}$ & $.566^{*}$ & $.604^{*}$ & $.629^{*}$ & 1 & $.695^{*}$ & $.632^{*}$ & $.701^{*}$ & $.695^{*}$ \\
\cline { 2 - 11 } & $\begin{array}{l}\text { Sig. } \\
\text { (bilater } \\
\text { al) }\end{array}$ & .000 & .000 & .000 & .000 & .000 & & .000 & .000 & .000 & .000 \\
\cline { 2 - 12 } & $\mathrm{N}$ & 384 & 384 & 383 & 383 & 383 & 384 & 383 & 384 & 383 & 383 \\
\hline
\end{tabular}

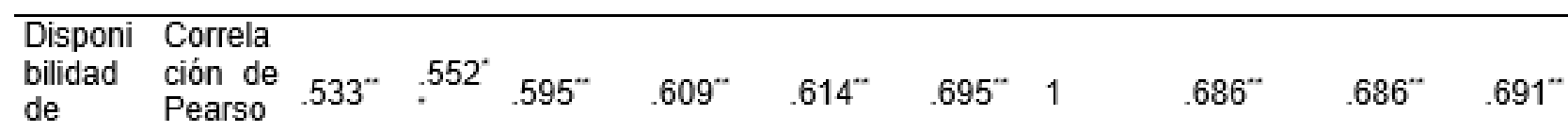

material $n$

\begin{tabular}{|c|c|c|c|c|c|c|c|c|c|c|c|}
\hline $\begin{array}{l}\text { es y } \\
\text { herrami } \\
\text { entas }\end{array}$ & $\begin{array}{l}\text { Sig. } \\
\text { (bilater } \\
\text { al) }\end{array}$ & .000 & .000 & .000 & .000 & .000 & .000 & & .000 & .000 & .000 \\
\hline & $\bar{N}$ & 383 & 383 & 382 & 382 & 382 & 383 & 383 & 383 & 382 & 382 \\
\hline
\end{tabular}

\begin{tabular}{|c|c|c|c|c|c|c|c|c|c|c|c|}
\hline $\begin{array}{l}\text { Respon } \\
\text { sabilida } \\
\text { d social } \\
\text { (Percep }\end{array}$ & $\begin{array}{l}\text { Correla } \\
\text { ción de } \\
\text { Pearso } \\
n\end{array}$ & $.650^{\circ}$ & $.750^{\circ}$ & $.732^{*}$ & $.724^{*}$ & $.652^{*}$ & $.632^{*}$ & $.686^{\circ}$ & 1 & $.836^{\circ}$ & $.805^{\circ}$ \\
\hline $\begin{array}{l}\text { la } \\
\text { segurid } \\
\text { ad y }\end{array}$ & $\begin{array}{l}\text { Sig. } \\
\text { (bilater } \\
\text { al) } \\
\end{array}$ & .000 & .000 & .000 & .000 & .000 & .000 & .000 & & .000 & .000 \\
\hline $\begin{array}{l}\text { salud } \\
\text { ocupaci } \\
\text { onal) }\end{array}$ & $\mathrm{N}$ & 384 & 384 & 383 & 383 & 383 & 384 & 383 & 384 & 383 & 383 \\
\hline $\begin{array}{l}\text { Respon } \\
\text { sabilida } \\
\text { d social } \\
\text { (Desarr }\end{array}$ & $\begin{array}{l}\text { Correla } \\
\text { ción de } \\
\text { Pearso } \\
n\end{array}$ & $.634^{*}$ & $.677^{\circ}$ & $.723^{*}$ & $.737^{\circ}$ & $.656^{\circ}$ & $.701^{*}$ & $.686^{\circ}$ & $.836^{\circ}$ & 1 & $.913^{*}$ \\
\hline $\begin{array}{l}\text { particip } \\
\text { ación } \\
\text { de los }\end{array}$ & $\begin{array}{l}\text { Sig. } \\
\text { (bilater } \\
\text { al) }\end{array}$ & .000 & .000 & .000 & .000 & .000 & .000 & .000 & .000 & & .000 \\
\hline $\begin{array}{l}\text { trabajad } \\
\text { ores) }\end{array}$ & $\overline{\mathrm{N}}$ & 383 & 383 & 382 & 382 & 382 & 383 & 382 & 383 & 383 & 383 \\
\hline $\begin{array}{l}\text { Respon } \\
\text { sabilida } \\
\text { d social } \\
\text { (Vincula }\end{array}$ & $\begin{array}{l}\text { Correla } \\
\text { ción de } \\
\text { Pearso } \\
n\end{array}$ & $.570^{\circ}$ & $.609^{\circ}$ & $.689^{*}$ & $.723^{*}$ & $.653^{*}$ & $.695^{\circ}$ & $.691^{*}$ & $.805^{*}$ & $.913^{*}$ & 1 \\
\hline $\begin{array}{l}\text { clon } \\
\text { compro } \\
\text { miso } \\
\text { con la }\end{array}$ & $\begin{array}{l}\text { Sig. } \\
\text { (bilater } \\
\text { al) } \\
\end{array}$ & .000 & .000 & .000 & .000 & .000 & .000 & .000 & .000 & .000 & \\
\hline $\begin{array}{l}\text { comuni } \\
\text { dad) }\end{array}$ & $\mathrm{N}$ & 383 & 383 & 382 & 382 & 382 & 383 & 382 & 383 & 383 & 383 \\
\hline
\end{tabular}

$\overline{* \star}$. La correlación es significativa en el nivel 0.01 ( 2 colas).

Fuente: Elaboración propia. 
Tabla 3. Áreas limpias de consumo de alimentos*Acceso a áreas de descanso tabulación cruzada

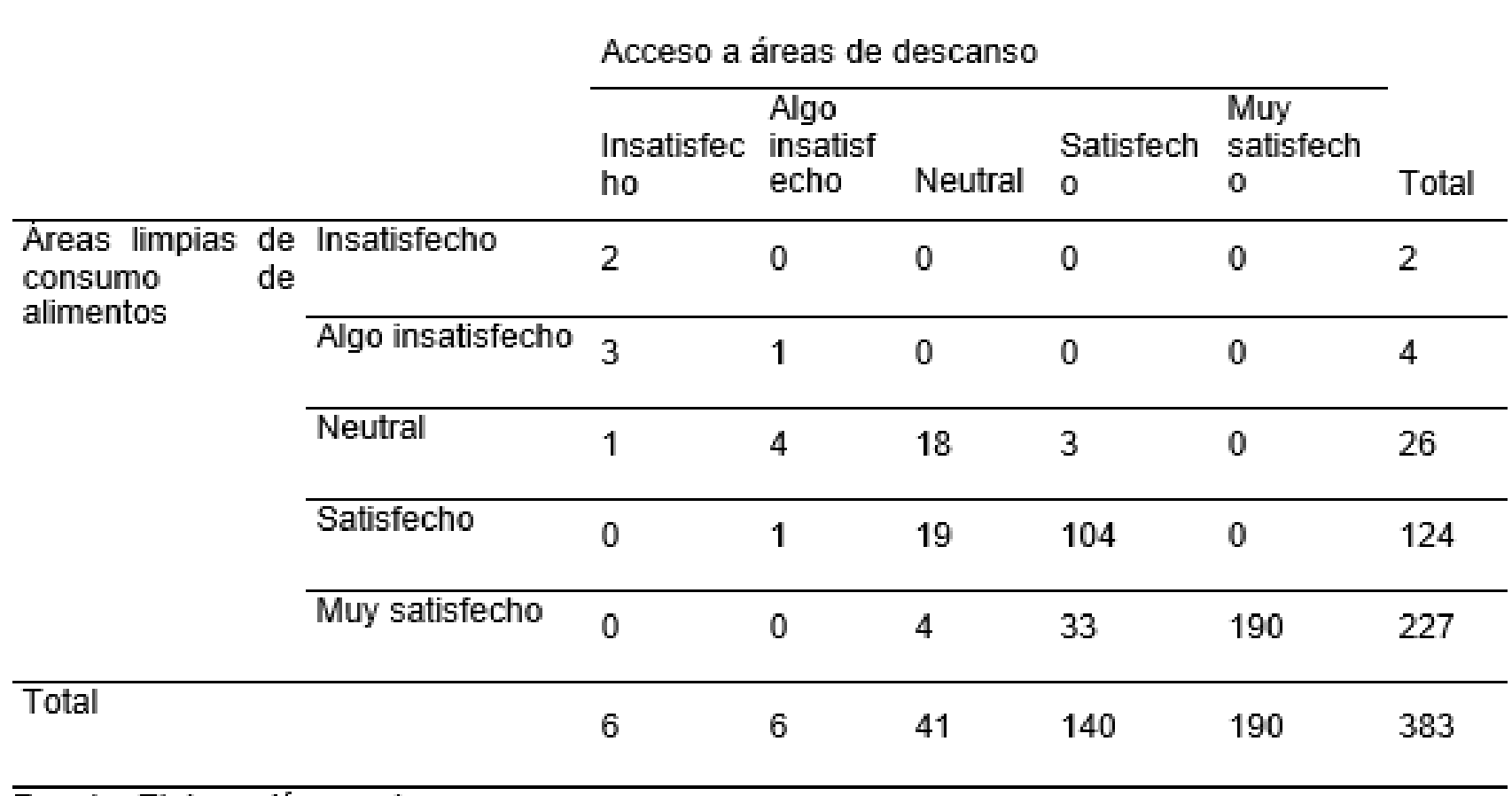

Fuente: Elaboración propia.

Tabla 4. Responsabilidad social (Percepción de la seguridad y salud ocupacional) *Responsabilidad social (Desarrollo y participación de los trabajadores) tabulación cruzada

\begin{tabular}{|c|c|c|c|c|c|c|}
\hline & \multicolumn{5}{|c|}{$\begin{array}{l}\text { Responsabilidad social (Desarrollo y participación de } \\
\text { los trabajadores) }\end{array}$} & \multirow[b]{2}{*}{ Total } \\
\hline & $\begin{array}{l}\text { Insatisfec } \\
\text { ho }\end{array}$ & $\begin{array}{l}\text { Algo } \\
\text { insatisf } \\
\text { echo }\end{array}$ & Neutral & Satisfecho & $\begin{array}{l}\text { Muy } \\
\text { satisfech } \\
0\end{array}$ & \\
\hline \multirow{4}{*}{$\begin{array}{l}\text { Responsabilidad } \\
\text { social } \\
\text { (Percepción de } \\
\text { la seguridad y } \\
\text { salud } \\
\text { ocupacional) }\end{array}$} & 4 & 0 & 0 & 0 & 0 & 4 \\
\hline & 1 & 4 & 0 & 0 & 0 & 5 \\
\hline & 0 & 2 & 10 & 1 & 0 & 13 \\
\hline & 1 & 7 & 34 & 89 & 3 & 134 \\
\hline Muy satisfecho & 0 & 0 & 1 & 33 & 193 & 227 \\
\hline Total & 6 & 13 & 45 & 123 & 196 & 383 \\
\hline
\end{tabular}

Fuente: Elaboración propia. 
Tabla 5 Responsabilidad social (Percepción de la seguridad y salud ocupacional) ${ }^{\star}$ Responsabilidad social (Vinculación y compromiso con la comunidad) tabulación cruzada

Responsabilidad social (Vinculación y compromiso con la comunidad)

\begin{tabular}{|c|c|c|c|c|c|c|c|}
\hline & & $\begin{array}{l}\text { Insatisfec } \\
\text { ho }\end{array}$ & $\begin{array}{l}\text { Algo } \\
\text { insatisf } \\
\text { echo }\end{array}$ & Neutral & $\begin{array}{l}\text { Satisfech } \\
0\end{array}$ & $\begin{array}{l}\text { Muy } \\
\text { satisfech } \\
0\end{array}$ & Total \\
\hline \multirow{5}{*}{$\begin{array}{l}\text { Responsabilidad } \\
\text { social } \\
\text { (Percepción de } \\
\text { la seguridad y } \\
\text { salud } \\
\text { ocupacional) }\end{array}$} & Insatisfecho & 4 & 0 & 0 & 0 & 0 & 4 \\
\hline & Algo insatisfecho & 1 & 4 & 0 & 0 & 0 & 5 \\
\hline & Neutral & 0 & 4 & 8 & 1 & 0 & 13 \\
\hline & Satisfecho & 0 & 9 & 44 & 80 & 1 & 134 \\
\hline & Muy satisfecho & 0 & 0 & 6 & 47 & 174 & 227 \\
\hline \multicolumn{2}{|l|}{ Total } & 5 & 17 & 58 & 128 & 175 & 383 \\
\hline
\end{tabular}

Fuente: Elaboración propia.

Tabla 6 Responsabilidad social (Desarrollo y participación de los trabajadores)Responsabilidad social (Vinculación y compromiso con la comunidad) tabulación cruzada

\begin{tabular}{|c|c|c|c|c|c|c|c|}
\hline & & \multicolumn{5}{|c|}{$\begin{array}{l}\text { Responsabilidad social (Vinculación y compromiso } \\
\text { con la comunidad) }\end{array}$} & \multirow[b]{2}{*}{ Total } \\
\hline & & $\begin{array}{l}\text { Insatisfec } \\
\text { ho }\end{array}$ & $\begin{array}{l}\text { Algo } \\
\text { insatisf } \\
\text { echo }\end{array}$ & Neutral & $\begin{array}{l}\text { Satisfech } \\
0\end{array}$ & $\begin{array}{l}\text { Muy } \\
\text { satisfech } \\
0\end{array}$ & \\
\hline \multirow{5}{*}{$\begin{array}{l}\text { Responsabilidad } \\
\text { social (Desarrollo y } \\
\text { participación de los } \\
\text { trabajadores) }\end{array}$} & Insatisfecho & 4 & 2 & 0 & 0 & 0 & 6 \\
\hline & $\begin{array}{l}\text { Algo } \\
\text { insatisfecho }\end{array}$ & 1 & 10 & 2 & 0 & 0 & 13 \\
\hline & Neutral & 0 & 5 & 38 & 2 & 0 & 45 \\
\hline & Satisfecho & 0 & 0 & 17 & 102 & 4 & 123 \\
\hline & Muy satisfecho & 0 & 0 & 1 & 24 & 171 & 196 \\
\hline \multicolumn{2}{|l|}{ Total } & 5 & 17 & 58 & 128 & 175 & 383 \\
\hline
\end{tabular}

Fuente: Elaboración propia. 


\section{Discusión}

En este apartado, se presentan los diversos análisis y la interpretación de resultados de la información reflejada mediante el procesamiento de datos del software SPSS-23, en el que se denotó la incidencia de la aplicación de la normativa Global Gap y su complemento GRASP en el cumplimiento de la filosofía de la Responsabilidad Social Empresarial a través del estudio de 13 indicadores claves.

Análisis de resultados de tres indicadores con reactivos dicotómicos:

Conjugando los indicadores, "Existencia de representante de reclamaciones, estabilidad laboral y afiliación al IESS" elaborados en base a preguntas dicotómicas, prevalece la percepción de los trabajadores con un 60.16\%, 73.89\% y $75 \%$ respectivamente, con un promedio del 69.68\% resultando un porcentaje significativo de la incidencia de la normativa frente al mejoramiento de la calidad de vida de los empleados en los últimos años, sin embargo cabe destacar que aún existe un 30.32\% de los trabajadores que no gozan de los mismos derechos de su mayoría por a o b razones dentro de las organizaciones, lo que preocupa y a la vez incita a crear medidas aún más rígidas para su total cumplimiento y observancia permanente.

Análisis de resultados de diez indicadores con reactivos politómicos:

Conjugando los indicadores sobresalientes en las diferentes tablas estadísticas descriptivas e inferenciales, se pudo evidenciar a través de la metodología indicada con anterioridad en donde " 1 " es lo más bajo y "5" lo más alto, que el indicador con una mayor media o mayor percepción positiva es el indicador de "Instalaciones de trabajo adecuadas" con un promedio de 4.68, siguiéndole el "acceso a sanitarios" con un 4.55 y en tercer lugar el "Acceso a áreas de descanso" con un promedio de 4.50
Así mismo los indicadores con una menor media o promedio, pero sin bajarse de los niveles inferiores: "Participación en capacitaciones" con un promedio de 4.00, "Remuneración justa según las funciones" con una media de 4.11, y en tercer lugar "Vinculación y compromiso con la comunidad" con un promedio de 4.18.

Se evidencia una distribución modal con el más alto valor de la investigación, situándose en "5". Con relación a la desviación estándar, demuestran en la mayoría de los indicadores una dispersión no muy significativa.

Cabe tomar en consideración que, a pesar del reflejo de valores positivos en las tablas y gráficos elaborados, aún no se cumple en su totalidad dicha normativa.

\section{Conclusiones}

Como demuestra la investigación, se logró determinar la incidencia de la aplicación de la normativa Global GAP y su complemento GRASP en el cumplimiento de la filosofía de la Responsabilidad Social Empresarial para la integración de sostenibilidad del sector agroalimentario evaluando la percepción de su parte obrera.

Los 13 indicadores juegan un papel relevante a la hora de definir si una empresa es responsable y si posee una sostenibilidad no sólo a corto sino a largo plazo, con un fuerte compromiso y confianza hacia sus empleados $y$, por ende, hacia la sociedad en general, o partes interesadas conocidos como stakeholders.

Los indicadores descritos en el informe, conforman los factores y las exigencias principales en cuanto a salud, seguridad y bienestar de los trabajadores que constan en la normativa Global GAP y su complemento GRASP, así como en los principios básicos de la Responsabilidad Social Empresarial direccionada a los diferentes sectores económicos y en este punto, a su sector agroalimentario.

Global GAP y su complemento GRASP representan muchos beneficios tanto para Ios trabajadores y sociedad, como para cada una 
de las organizaciones en particular, abriendo puertas al mercado internacional, en donde las exigencias y la preocupación de la parte social y medioambiental son aún mayores que la del mercado nacional.

\section{Referencias bibliográficas}

Abadía, R., y Melgarejo, J. (2017). El sector agroalimentario: sostenibilidad, cooperación y expansión. Alicante, España: Ayuntamiento de Orihuela y Universidad de Alicante. Recuperado el 02 de Octubre de 2019 , de https://books. google.es/books?id=myCADwAAOBAJ \&printsec $=$ frontcover $\&$ hl $=$ es $\&$ source $=g$ bs_ge_summary_r\&cad $=0 \# \vee=$ onepage $\&$ q\&f=false

Almeida, M., y Arrechavaleta, N. (2018). Responsabilidad social empresarial y sus limitaciones en el contexto académico universitario. Revista Cubana Educación Superior, 37(2), 87-103. Recuperado el 15 de Agosto de 2019, de https://pdfs. semanticscholar.org/ce93/993079cfc9d 29176bc8a00d4dd45f62ba95a.pdf

Anderson, D., Sweeney, D., y Williams, T. (2008). Estadística para administración y economía (Décima ed.). México,D.F: Cengage Learning.

Antelo, Y., y Robaina, D. (2014). Análisis de la Responsabilidad Social Empresarial basado en un modelo de Lógica Difusa Compensatoria. Ingeniería Industrial, 36(1), 58-69. Recuperado el 17 de Octubre de 2019 , de http://scielo.sld.cu/ pdf/rii/v36n1/rii07 115.pdf

Banco Central del Ecuador. (Septiembre de 2019). Banco Central del Ecuador. Recuperado el 16 de Octubre de 2019 , de https://mww.bce.fin.ec/index.php/ boletines-de-prensa-archivo/item/1206la-econom\%C3\%ADa-ecuatorianacreci\%C3\%B3-03-en-el-segundotrimestre-de-2019
Barros, M., Retamozo, M., y González, D. (2015). Responsabilidad social empresarial en la ciudad de Barranquilla. Revista Semilla( 1 ), 80-87. Recuperado el 03 de Octubre de 2019, de http://ojsinvestigacion. unilibrebaq.edu.co/ojsinvestigacion/ index.php/semilladice/article/view/448

Bohórquez, L. (2013). La organización empresarial como sistema adaptativo complejo. Estudios Gerenciales, 29(127), 258-265. Recuperado el 11 de Octubre de 2019, de https://mww.redalyc.org/ articulo.oa?id=21229175015

Burbano, J., y Fernández , M. (2018). Diagnóstico del sector agroalimentario de Ecuador: una aproximación al ecosistema agroemprendedor. Anales Científicos, 79(2), 519-525. Recuperado el 11 de Octubre de 2019 , de https://dialnet.unirioja.es/servlet/ articulo?codigo $=6830785$

Calderón, H., y Kolbe, D. (2016). Capacidades dinámicas en el proceso de internacionalización de las empresas de distribución de productos agroalimentarios. Economía Agraria y Recursos Natuales, 16(2), 05-32. Recuperado el 17 de Octubre de 2019, de https://dialnet.unirioja.es/servlet/ articulo?codigo $=5819234$

Cattaneo, C., y Bocchicchio, A. (2019). Dinámica sociorganizacional en el sistema agroalimentario. Revista mexicana de sociología, 81(1), 7-35. Recuperado el 11 de Octubre de 2019, de http://mmw. scielo.org.mx/pdf/rms/v8 $1 \mathrm{n} 1 / 0188$ 2503-rms-81-0 1-7.pdf

El Comercio. 101 de Enero de 2019). El Comercio. Recuperado el 17 de Octubre de 2019, de https://muw.elcomercio. com/pages/especial-enero-agro.html

FAO, FIDA, UNICEF, PMA y OMS. (2018). EI estado de la seguridad alimentaria y la nutrición en el mundo. Fomentando 
la resiliencia climática en aras de la seguridad alimentaria y la nutrición. Roma: FAO. Recuperado el 31 de 11 de 2019, de http://muw.fao.org/3/i9553es/ i9553es.pdf

García, A., Caraus, M., Iglesias, T., y Maldonado , J. (2018). Regulación, innovación y competitividad en el sector de la alimentación. Revista de coyuntura y perspectivas, 3(2), 33-56. Recuperado el 11 de 10 de 2019, de http://mun. revistasbolivianas.org.bo/pdf/ec/v3n2/ v3n2_a03.pdf

García, A., Guzmán, A., y Mendoza, J. (2017). Valorando la RSE por los stakeholdersinternos: caso sector de la construcción en Bucaramanga. Revista de Investigaciones, 9(1), 107-115. Recuperado el 15 de Agosto de 2019 , de http://mmw.udi.edu. co/revistainvestigaciones/index.php/ID/ article/view/119

García, L., y Wahren, J. (2016). Seguridad Alimentaria vs. Soberanía Alimentaria: La cuestión alimentaria y el modelo del. Trabajo y Sociedad(26), 327-340. Recuperado el 17 de Octubre de 2019 , de https://dialnet.unirioja.es/servlet/ articulo?codigo $=6869637$

GlobalGAP. (2019). GlobalGAP. Recuperado el 03 de Octubre de 2019, de https:// www.globalgap.org/es/for-producers/ globalg.a.p.-add-on/grasp/

Jiménez, D., y Pérez, L. (20 16). La Representación Simbólica de la Responsabilidad Social Empresarial (RSE): El caso Santa Marta. Investigación e Innovación en Ingenierias, 4(2), 72-1 18. Recuperado el 11 de Octubre de 2019 , de http://revistas.unisimon.edu. co/index.php/innovacioning/article/ view/2487

Lind, D., Marchal, W., y Wathen, S. (2012). Estadística aplicada a los negocios y la economía (Décimo quinta ed.). México: Mcgraw-Hill.
López, M., Perusquía, J., Valladares, O., Villalón, R., y Ramírez, M. (2015). La responsabilidad social empresarial, compromiso con la comunidad y el cuidado del medioambiente. Sotavento, 1(26), 54-60. Recuperado el 16 de Octubre de 2019 , de https://revistas.uexternado.edu.co/ index.php/sotavento/article/view/4686

Marquina, P., y Reficco, E. (2015). Impacto de la responsabilidad social empresarial en el comportamiento de compra y disposición a pagar de consumidores bogotanos. Estudios Gerenciales, 31(137), 373-382. Recuperado el 15 de Octubre de 2019 , de https://muw.sciencedirect.com/ science/article/pii/SO 123592315000558

Martínez, M., y Rosset, P. (2015). Soberanía alimentaria, Agroecología y Recampesinización. Soberania Alimentar (SOBAL) e Segurança Alimentar e Nutricional (SAN) na América Latina e Caribe, 25(47), 111-134. Recuperado el 11 de Octubre de 2019 , de https://foodfirst. org/wp-content/uploads/2016/02/ Agroecolog\%C3\%ADa-territoriorecampesinizaci\% C $3 \%$ B $3 n-y$ movimientos-sociales.pdf

Ministerio de Producción, Comercio Exterior, Inversiones y Pesca. (Septiembre de 2019). Pro Ecuador. Recuperado el 12 de Octubre de 2019, de https://mm. proecuador.gob.ec/informe-mensual-decomercio-septiembre-2019/

Ministerio de Trabajo. (Enero de 2020). Ministerio de Trabajo. Recuperado el 15 de Enero de 2020, de http://muw.trabajo.gob.ec/ creacion-de-organizaciones-laborales/

Morán, C., Rodriguez, L., Torres, M., Aguilar, A., y Villalta, M. (Julio-Diciembre de 2016). Stakeholders, responsabilidad social en ecuador. CTU Cientifica y Tencológica UPSE, 3(2), 21-30. Recuperado el 03 de Octubre de 2019, de https://incyt.upse. edu.ec/ciencia/revistas/index.php/rctu/ article/view/147 
Olmos, X. (Diciembre de 2017). Comisión Económica para América Latina y el Caribe (CEPAL). Recuperado el 12 de Octubre de 2019, de https://repositorio.cepal. org/bitstream/handle/1 1362/43288/1/ s1700618_es.pdf

Patlán, J. (2016). Derechos laborales: una mirada al derecho a la calidad de vida en el trabajo. Ciencia Ergo Sum, 23(2), 121-133. Recuperado el 15 de Enero de 2020, de https://muw.redalyc.org/ jatsRepo/ 104/10446094004/html/index. html

Rincon, N., Figueredo, C., y Salazar, N. (2015). Impacto de la aplicación de la norma GlobalGAP, en el sector agroalimentario Latinoaméricano. Revista Colombiana de Investigaciones Agroindustriales, 2, 84-97. Recuperado el 17 de Octubre de 2019, de http://revistas.sena.edu.co/ index.php/recia/article/view/173

Ruíz, S. (Abril de 2016 ). El Sector Agroalimentario y su competitividad a partir de modelos asociativos. Ingeniería Industrial, XXXVII|3), 323-332. Recuperado el 11 de Octubre de 2019, de http://scielo.sld.cu/ pdf/rii/v37n3/rii $110316 . p d f$

Tapia, A., Gavilánez, M., Jácome, S., y Balseca , J. (2018). La responsabilidad social empresarial: Un desafío para la sostenibilidad de las empresas del Ecuador. Empresa, Investigación y pensamiento crítico, 7/4), 68-89. Recuperado el 16 de Octubre de 2019 , de https://dialnet.unirioja.es/servlet/ articulo?codigo=6708534

Uribe, M., Orjuela, D., y Moreno, X. (2016). RSE de la Universidad del Tolima frente al Stakeholder proveedores. Dimensión Empresarial, 14(2), 115-126. Recuperado el 17 de Octubre de 2019, de http:// www.scielo.org.co/pdf/diem/v14n2/ v14n2a08.pdf
Villacís, A., y Reis, M. (2015). Análisis de la vulnerabilidad laboral y los determinantes del trabajo decente. El caso de Ecuador 2008-2011. Revista de Economía del Rosario, 18(2), 157-185. Recuperado el 14 de 02 de 2020, de https://Mmw. urosario.edu.co/facultad-economia/ Documentos/Publicaciones/0 1-RevEconomia-UR-18_2_AVillacis-et-al.pdf

Wulf, E. (2018). Responsabilidad Social Empresarial: Un desafio corporativo. Santiago de Chile: Editorial Universidad de la Serena. Recuperado el 12 de Agosto de 2019, de https://books.google.com. ec/books?id=7JBxDwAAOBAJ\&printsec =frontcover \&hl=es\&source=gbs_ge_sum mary_r\&cad $=0 \# v=$ onepage $\& q \& f=$ false

Zivko, D., Bogetic, S., y Dordevic, D. (2015). El papel de GAP global: en la mejora de la competitividad de la industria agroalimentaria. Economía de la agricultura, 62(3), 583-597. Recuperado el 12 de Octubre de 2019, de http:// www.ea.bg.ac.rs/index.php/EA/article/ view/270/252 